Pacific Journal of Mathematics

A COUNTER-EXAMPLE TO A LEMMA OF SKORNJAKOV 


\section{A COUNTER-EXAMPLE TO A LEMMA OF SKORNJAKOV}

\section{B. L. OSOFSKY}

In his paper, Rings with injective cyclic modules, translated in Soviet Mathematics 4 (1963), p. 36-39, L. A. Skornjakov states the following lemma: If a cyclic $R$-module $M$ and all its cyclic submodules are injective, then the partially ordered set of cyclic submodules of $M$ is a complete, complemented lattice.

An example is constructed to show that this lemma is false, thus invalidating Skornjakov's proof of the theorem: Let $R$ be a ring all of whose cyclic modules are injective. Then $R$ is semi-simple Artin. The theorem, however, is true. (See Osofsky [4].)

The theorem, however, is true. (See Osofsky [4].)

In this paper, all rings have identity and all modules are unital left modules. $\mathfrak{M}_{\mathbb{R}}$ will denote the category of $R$-modules, and ${ }_{R} M$ will signify $M \in_{R} \mathfrak{M}$.

Let $Q$ be a commutative, left self injective, regular, non-Artin ring, and let $I$ be a maximal ideal of $Q$ which is not a direct summand of ${ }_{Q} Q$. (For example, let $Q$ be a direct product of fields, and $I$ a maximal ideal containing their direct sum.) Let $N=Q \oplus Q / I$. We observe the following:

1. ${ }_{Q} N$ is injective. $Q$ is injective by hypothesis, and $Q / I$ is a simple module over the commutative regular ring $Q$; hence injective by a theorem of Kaplansky. (See [5].)

2. ${ }_{Q} M \subseteq{ }_{Q} N$ is a direct summand of ${ }_{Q} N$ if and only if ${ }_{Q} M$ is finitely generated. If ${ }_{Q} M$ is a direct summand of ${ }_{Q} N,{ }_{Q} M$ is generated by the projections of $(1,0+I)$ and $(0,1+I)$. If ${ }_{Q} M$ is finitely generated, and $\pi$ is the projection of $N$ onto $(Q, 0+I)$, then $\pi\left({ }_{Q} M\right)$ is finitely generated. Hence $\pi\left({ }_{Q} M\right)$ is a direct summand of ${ }_{Q} Q$. (See von Neumann [6].) Say $Q=\pi\left({ }_{Q} M\right) \oplus K$. Since $\pi\left({ }_{Q} M\right)$ is projective (it is a direct summand of $Q),{ }_{Q} M=\left(\pi\left({ }_{Q} M\right)\right)^{\prime} \oplus\left(\operatorname{Ker} \pi \cap{ }_{Q} M\right)$. Since $Q / I$ is simple, $Q / I=\left(\operatorname{Ker} \pi \cap_{Q} M\right) \oplus K_{2}$ where $K_{2}=0$ or $Q / I$. Then $N=M \oplus K \oplus K_{2}$.

3. The direct summands of $N$ do not form a lattice. In particular, $Q(1,0+I) \cap Q(1,1+I)=(I, 0+I)$ is not a direct summand

Received August 5, 1964 and in revised form March 18, 1965. The author gratefully acknowledges support from the National Science Foundation under grant GP-1741. The author wishes to thank the referee for simplifying and clarifying her original example, and for several very constructive suggestions on the presentation. 
of $(Q, 0+I)$, hence not of $N$.

$N$ is not a counter-example to Skornjakov's lemma, since $N$ is not cyclic. However, properties 1,2 and 3 are preserved under category isomorphisms. For we have:

Proposition. ${ }_{R} M$ is finitely generated $\Leftrightarrow$ the union of a linearly ordered chain of proper submodules is proper.

Proof. $\Rightarrow$ Let $M=\sum_{i=1}^{n} R x_{i}$, and let $\left\{N_{\mu}\right\}$ be a linearly ordered chain of submodules whose union is $M$. If $x_{i} \in N_{\mu_{i}}$, then $\left\{x_{i} \mid i=\right.$ $1, \cdots, n\} \subseteq N_{\nu}$, where $\nu=\max \left\{\mu_{i} \mid 1 \leqq i \leqq n\right\}$. Then $M=N_{\nu}$.

$\Leftarrow$ Given ${ }_{R} M$, let $\$$ be the smallest cardinal such that $M$ has a generating set of cardinality $\aleph$. Index such a generating set $\left\{x_{\mu}\right\}$ by $\{\mu \mid \mu<\Omega\}$, where $\Omega$ is the first ordinal of cardinality $\boldsymbol{~} *$. Then $\left\{\sum_{\nu \leqq \mu} R x_{\nu}\right\}$ is a linearly ordered chain of submodules whose union is $M$. If $\Omega$ is a limit ordinal (that is, if $\mathcal{H}$ is infinite), then each $\sum_{\nu \leqq \mu} R x_{\nu}$ is generated by less than $\$$ elements; hence proper.

Thus $M$ finitely generated corresponds to the categorical property that the collection of nonepimorphic monomorphisms into $M$ is inductive under the ordering: $f \leqq g$ if and only if there is an $h$ with $f=g h{ }^{1}$

Let $R=\operatorname{Hom}_{Q}(Q \oplus Q, Q \oplus Q)$. By Morita [3], Theorem 3.4, the functor $\operatorname{Hom}_{Q}(Q \oplus Q, \quad):{ }_{Q} \mathfrak{M} \rightarrow{ }_{R} \mathfrak{M}$ is a category isomorphism. Hence ${ }_{R} M=\operatorname{Hom}_{Q}(Q \oplus Q, N)$ has properties $1,2,3$. Moreover, if $K=$ $\{\lambda \in R \mid(Q \oplus Q) \lambda \subseteq(0, I)\}$, then $M$ is isomorphic to $R / K$ since ${ }_{Q}(Q \oplus Q)$ projective implies the natural map from $R=\operatorname{Hom}_{Q}(Q \oplus Q, Q \oplus Q) \rightarrow$ $\operatorname{Hom}_{Q}(Q \oplus Q, Q \oplus Q / I)=M$ is an epimorphism. Hence $M$ is cyclic, and as in 2, every direct summand of $M$ is cyclic. Thus $M$ is the required counter-example.

We conclude with the observation that the technique used in 2 gives us a categorical equivalence to regular rings which is closer to the usual definition than Auslander's theorem that $R$ is regular if and only if the global flat dimension of $R$ is 0 . (See Auslander [1].)

$P \in{ }_{R} \mathbb{M}$ is a progenerator if it is finitely generated, projective, and every $M \in_{R} \mathfrak{M}$ is an epimorphic image of a direct sum of copies of $P$.

Proposition. The following are equivalent:

1 Although the categorical definition of finitely generated appears in H. Bass, The Morita theorems, University of Oregon (mimeographed notes), the author found no proof in the literature that this is equivalent to the module definition, and so is including this proof for completeness. 
(a) $R$ is regular.

(b) Every finitely generated submodule of a projective module is a direct summand.

(c) There is a progenerator $P \in_{R} \mathfrak{M}$ such that every finitely generated submodule of $P$ is a direct summand.

Proof. $\quad(b) \Rightarrow$ (a) (See von Neumann [6].)

(a) $\Rightarrow$ (c) $R$ is a progenerator with the required properties.

(c) $\Rightarrow$ (b) Let $N$ be a projective module, $M$ a finitely generated submodule.

Let $P$ be the progenerator of condition (c). Then there is an epimorphism $f: \Sigma \oplus P_{i} \rightarrow N$. Since $N$ is projective, this splits and $\Sigma \oplus P_{i}=N^{\prime} \oplus$ ker $f$, where $N^{\prime} \approx N$. Thus $M$ is a finitely generated submodule of $\Sigma \oplus P_{i}$, and if it is a direct summand of $\Sigma \oplus P_{i}$, it is a direct summand of $N$.

Since $M$ is finitely generated, $M$ is contained in a finite direct sum $\sum_{j=1}^{n} P_{j}$. If $n=1, M$ is a direct summand of $P$ by hypothesis, and hence a direct summand of $\Sigma \oplus P_{i}$. Now assume any finitely generated submodule of $\sum_{j=1}^{n-1} P_{j}$ is a direct summand. Let $\pi_{n}$ be the projection of $\sum_{j=1}^{n} P_{j}$ onto $P_{n}$. Then $\pi_{n}(M)$ is a direct summand of $P_{n}$, say $P_{n}=\pi_{n}(M) \oplus K_{1}$. Ker $\pi_{n} \cap M$ is a direct summand of $M$, hence finitely generated. Then by the induction hypothesis, $\sum_{j=1}^{n-1} P_{j}=$ $\left(\operatorname{Ker} \pi_{n} \cap M\right) \oplus K_{2}$. Then $\sum_{j=1}^{n} P_{j}=K_{1} \oplus K_{2} \oplus M$, so $M$ is a direct summand of $\Sigma \oplus P_{i}$, and hence of $N$.

\section{REFERENCES}

1. M. Auslander, On regular group rings, Proc. Amer. Math. Soc. 8 (1957), 658-664.

2. H. Cartan and S. Eilenberg, Homological Algebra, Princeton University Press, 1956.

3. K. Morita, Duality for modules and its applications to the theory of rings with minimum condition, Tokyo Kyoiku Daigaku 6 (1958), 83-142.

4. B. L. Osofsky, Rings all of whose finitely generated modules are injective, Pacific

J. Math. 14 (1964), 645-650.

5. A. Rosenberg and D. Zelinsky, Finiteness of the injective hull, Math. Zeit. 70 (1959), 372-380.

6. J. von Neumann, On regular rings, Proc. Nat. Acad. Sc. (USA) 22 (1936), 707-713.

Rutgers, The State University 



\section{PACIFIC JOURNAL OF MATHEMATICS}

\section{EDITORS}

\author{
H. Samelson \\ Stanford University \\ Stanford, California \\ R. M. Blumenthal \\ University of Washington \\ Seattle, Washington 98105
}

\author{
J. Dugundu \\ University of Southern California \\ Los Angeles, California 90007 \\ *Richard Arens \\ University of California \\ Los Angeles, California 90024
}

\section{ASSOCIATE EDITORS}
E. F. BeCKENBACH
B. H. NeUMANN
F. WOLF
K. YosidA

\section{SUPPORTING INSTITUTIONS}

\author{
UNIVERSITY OF BRITISH COLUMBIA \\ CALIFORNIA INSTITUTE OF TECHNOLOGY \\ UNIVERSITY OF CALIFORNIA \\ MONTANA STATE UNIVERSITY \\ UNIVERSITY OF NEVADA \\ NEW MEXICO STATE UNIVERSITY \\ OREGON STATE UNIVERSITY \\ UNIVERSITY OF OREGON \\ OSAKA UNIVERSITY \\ UNIVERSITY OF SOUTHERN CALIFORNIA
}

\author{
STANFORD UNIVERSITY \\ UNIVERSITY OF TOKYO \\ UNIVERSITY OF UTAH \\ WASHINGTON STATE UNIVERSITY \\ UNIVERSITY OF WASHINGTON \\ * * * * \\ AMERICAN MATHEMATICAL SOCIETY \\ CALIFORNIA RESEARCH CORPORATION \\ SPACE TECHNOLOGY LABORATORIES \\ NAVAL ORDNANCE TEST STATION
}

Mathematical papers intended for publication in the Pacific Journal of Mathematics should by typewritten (double spaced). The first paragraph or two must be capable of being used separately as a synopsis of the entire paper. It should not contain references to the bibliography. No separate author's resumé is required. Manuscripts may be sent to any one of the four editors. All other communications to the editors should be addressed to the managing editor, Richard Arens, at the University of California, Los Angeles, California 90024.

50 reprints per author of each article are furnished free of charge; additional copies may be obtained at cost in multiples of 50 .

The Pacific Journal of Mathematics is published quarterly, in March, June, September, and December. Effective with Volume 13 the price per volume (4 numbers) is $\$ 18.00$; single issues, $\$ 5.00$. Special price for current issues to individual faculty members of supporting institutions and to individual members of the American Mathematical Society: $\$ 8.00$ per volume; single issues $\$ 2.50$. Back numbers are available.

Subscriptions, orders for back numbers, and changes of address should be sent to Pacific Journal of Mathematics, 103 Highland Boulevard, Berkeley 8, California.

Printed at Kokusai Bunken Insatsusha (International Academic Printing Co., Ltd.), No. 6, 2-chome, Fujimi-cho, Chiyoda-ku, Tokyo, Japan.

PUBLISHED BY PACIFIC JOURNAL OF MATHEMATICS, A NON-PROFIT CORPORATION

The Supporting Institutions listed above contribute to the cost of publication of this Journal, but they are not owners or publishers and have no responsibility for its content or policies.

* Basil Gordon, Acting Managing Editor until February 1, 1966. 


\section{Pacific Journal of Mathematics}

\section{Vol. 15, No. $3 \quad$ November, 1965}

David R. Arterburn and Robert James Whitley, Projections in the space of

bounded linear operators .................................

Robert McCallum Blumenthal, Joram Lindenstrauss and Robert Ralph Phelps,

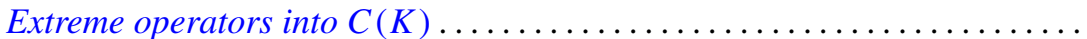

L. Carlitz, A note on multiple exponential sums ................... 757

Joseph A. Cima, A nonnormal Blaschke-quotient .................... 767

Paul Civin and Bertram Yood, Lie and Jordan structures in Banach algebras . . . 775

Luther Elic Claborn, Dedekind domains: Overrings and semi-prime

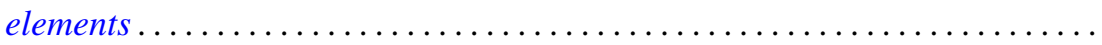

799

Luther Elic Claborn, Note generalizing a result of Samuel's .............. 805

George Bernard Dantzig, E. Eisenberg and Richard Warren Cottle, Symmetric

dual nonlinear programs ................................... 809

Philip J. Davis, Simple quadratures in the complex plane ............... 813

Edward Richard Fadell, On a coincidence theorem of F. B. Fuller ............ 825

Delbert Ray Fulkerson and Oliver Gross, Incidence matrices and interval

graphs ........................................ 835

Larry Charles Grove, Tensor products over $H^{*}$-algebras ..................

Deborah Tepper Haimo, $L^{2}$ expansions in terms of generalized heat polynomials

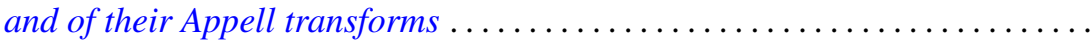

I. Martin (Irving) Isaacs and Donald Steven Passman, A chardcterization of groups in terms of the degrees of their characters ..........

Donald Gordon James, Integral invariants for vectors over local fields........ 905

Fred Krakowski, A remark on the lemma of Gauss ................... 917

Marvin David Marcus and H. Minc, A subdeterminant inequality ........... 921

Kevin Mor McCrimmon, Norms and noncommutative Jordan algebras ........ 925

Donald Earl Myers, Topologies for Laplace transform spaces ............... 957

Olav Njstad, On some classes of nearly open sets .................... 961

Milton Philip Olson, A characterization of conditional probability ........... 971

Barbara Osofsky, A counter-example to a lemma of Skornjakov .............. 985

Sidney Charles Port, Ratio limit theorems for Markov chains ............... 989

George A. Reid, A generalisation of $W^{*}$-algebras ...................... 1019

Robert Wells Ritchie, Classes of recursive functions based on Ackermann's

function ........................................... 1027

Thomas Lawrence Sherman, Properties of solutions of $n$th order linear

differential equations ........................................ 1045

Ernst Snapper, Inflation and deflation for all dimensions . .............. 1061

Kondagunta Sundaresan, On the strict and uniform convexity of certain Banach

spaces............................................. 1083

Frank J. Wagner, Maximal convex filters in a locally convex space .......... 1087

Joseph Albert Wolf, Translation-invariant function algebras on compact 